\title{
How the Body Position Can Influence High-resolution Manometry Results in the Study of Esophageal Dysphagia and Gastroesophageal Reflux Disease
}

\author{
Constanza Ciriza-de-los-Ríos, ${ }^{1 *}$ Fernando Canga-Rodríguez-Valcárcel, ${ }^{1}$ David Lora-Pablos, ${ }^{2}$ Javier De-La-Cruz-Bértolo, ${ }^{2}$ \\ Isabel Castel-de-Lucas, ${ }^{1}$ and Gregorio Castellano-Tortajada ${ }^{1}$ \\ ${ }^{1}$ Department of Gastroenterology, Hospital Universitario 12 de Octubre, Madrid, Spain; and ${ }^{2}$ Clinical Research Unit, IMAS12-CIBERESP, Hospital \\ Universitario 12 de Octubre, Madrid, Spain
}

\section{Background/Aims}

The body position can influence esophageal motility data obtained with high-resolution manometry (HRM). To examine whether the body position influences HRM diagnoses in patients with esophageal dysphagia and gastroesophageal reflux disease (GERD).

\section{Methods}

HRM (Manoscan) was performed in 99 patients in the sitting and supine positions; 49 had dysphagia and 50 had GERD assessed by 24-hour pH monitoring. HRM plots were analyzed according to the Chicago classification.

\section{Results}

HRM results varied in the final diagnoses of the esophageal body (EB) in patients with dysphagia $(P=0.024)$, the result being more distal spasm and weak peristalsis while sitting. In patients with GERD, the HRM diagnoses of the lower esophageal sphincter (LES), the esophagogastric junction (EGJ) morphology, and EB varied depending on the position; $(P=0.063, P=0.017$, $P=0.041$ respectively). Hypotensive LES, EGJ type III (hiatal hernia), and weak peristalsis were more frequently identified in the sitting position. The reliability (kappa) of the position influencing HRM diagnoses was similar in dysphagia and GERD ("LES diagnosis": dysphagia 0.32 [0.14-0.49] and GERD 0.31 [0.10-0.52], $P=0.960 ;$ "EB diagnosis": dysphagia 0.49 [0.30-0.69] and GERD $0.39[0.20-0.59], P=0.480)$. The reliability in "EGJ morphology" studies was higher in dysphagia 0.81 (0.68-0.94) than in GERD $0.55(0.37-0.73), P=0.020$

Received: September 21, 2014 Revised: December 31, 2014 Accepted: January 10, 2015

(c) This is an Open Access article distributed under the terms of the Creative Commons Attribution Non-Commercial License (http://creativecommons. org/licenses/by-nc/4.0) which permits unrestricted non-commercial use, distribution, and reproduction in any medium, provided the original work is properly cited.

*Correspondence: Constanza Ciriza-de-los-Ríos, MD, PhD

Department of Gastroenterology, Hospital Universitario12 de Octubre, Avenida de Córdoba s/n, Madrid 28041, Spain Tel: +34-609704009, E-mail: constanzacarpa@gmail.com

Financial support: None.

Conflicts of interest: None.

Author contributions: Constanza Ciriza-de-los-Ríos and Fernando Canga-Rodríguez-Valcárcel contributed to the study concept and design, acquisition of data, analysis and interpretation of data, drafting of the manuscript, critical revision of the manuscript for important intellectual content, and study supervision; David Lora-Pablos and Javier De-La-Cruz-Bértolo contributed to the statistical analysis and critical revision of the manuscript for important intellectual content; Isabel Castel-de-Lucas contributed to acquisition of data; and Gregorio Castellano-Tortajada contributed to the critical revision of the manuscript for important intellectual content and study supervision.

ORCID: Constanza Ciriza-de-los-Ríos, http://orcid number: orcid.org/0000-0002-1217-1881; Fernando Canga-Rodríguez-Valcárcel, http://orcid.org/0000-0002-2569-4470; David Lora-Pablos, http://ocid.org/0000-0002-3317-5689; Javier De-La-Cruz-Bértolo, orcid.org/0000-0002-2010-4128; Isabel Castel-de-Lucas, http://ordid.org/ 0000-0003-3014-7778. 


\section{Conclusions}

HRM results varied according to the position in patients with dysphagia and GERD. Weak peristalsis was more frequently diagnosed while sitting in dysphagia and GERD. Hypotensive LES and EGJ type III (hiatal hernia) were also more frequently diagnosed in the sitting position in patients with GERD.

(J Neurogastroenterol Motil 2015;21:370-379)

\section{Key Words}

Esophageal motility disorders; Gastroesophageal reflux; Manometry; Peristalsis; Supine position

\section{Introduction}

High-resolution manometry (HRM) is undoubtedly a breakthrough in esophageal manometry testing. ${ }^{1-6}$ It nevertheless involves some challenges such as determining the optimal protocol for HRM in clinical practice. ${ }^{7-9}$ The test is usually performed in the supine position. ${ }^{6,10}$ The published normative reference values are for this position too and the Chicago classification ${ }^{7}$ is applied to them. Recently a European group has also published normative values for the supine position obtained with the same equipment. These values have shown both similarities and discrepancies as compared to the ones published by the Chicago group. ${ }^{11}$

However, the normal eating position is upright and dysphagia by definition occurs while eating. Different methods have been applied in clinical esophageal manometry testing. The sitting position protocol is used based on the argument that it is the position in which swallowing happens in everyday life. Later on, HRM was adopted with the Chicago classification criteria for interpretation. There is a recent study on how the body position affects the normative ranges and cut-off values of esophageal pressure topography and metrics utilized in the Chicago classification. The results showed there were differences depending on the body position. ${ }^{12}$

Gastroesophageal reflux disease (GERD) can be associated with hypotensive lower esophageal sphincter (LES), decreased overall LES and intra-abdominal LES lengths and hiatal hernia. ${ }^{13,14}$ Motility abnormalities have been described more frequently in the sitting position. ${ }^{14,15}$ It has been reported that the position impacts LES competency in those with upright reflux and would not be detected in supine manometry. ${ }^{16}$

The aim of this study is to determine how much the body position alters the results obtained with HRM and eventually, the diagnosis of esophageal motility disorders in patients with esophageal dysphagia and GERD assessed by 24-hour pH moni- toring. HRM is primarily indicated for the study of dysphagia. It is not directly indicated for the study of GERD, but it can nevertheless identify some disorders related to GERD, such as hypotensive LES, esophagogastric junction (EGJ) disruption or weak peristalsis. This is the background upon which the study population should be chosen.

\section{Materials and Methods}

\section{Patients}

This is an observational cross-sectional study. One hundred and sixty consecutive over 18-year-old patients with dysphagia or GERD symptoms were studied in our esophageal motility laboratory between 2010 and 2011. Symptoms were evaluated using a standard analogical questionnaire with scores of $0-3$ ( 0 , none; 1 , mild; 2 , moderate; 3 , severe).

Inclusion criteria were (1) signed informed consent, (2) minimum age of 18 years, and (3) patients with moderate to severe symptoms. Exclusion criteria were (1) patients with esophageal dysphagia with concomitant reflux symptoms, as the correlation between esophageal motor disorder and reflux symptoms are not very consistent ${ }^{17}$ and to avoid any overlapping of symptoms between the 2 study groups, (2) previous surgical or endoscopic treatments on the EGJ, (3) GERD symptoms and normal pH monitoring, and (4) presence of organic disease by barium esophagogram or upper gastrointestinal endoscopy. From the initially enrolled patients, 10 patients who had undergone treatments on the EGJ, 10 patients with dysphagia and concomitant GERD symptoms and 31 patients with GERD symptoms but normal $\mathrm{pH}$ result were excluded according to these criteria. Ten patients who could not complete the study protocol in both positions because of poor tolerance to the procedure were also excluded.

Finally 99 patients (59 females) were included, 49 of them having dysphagia and 50 having GERD (Fig. 1). The demo- 


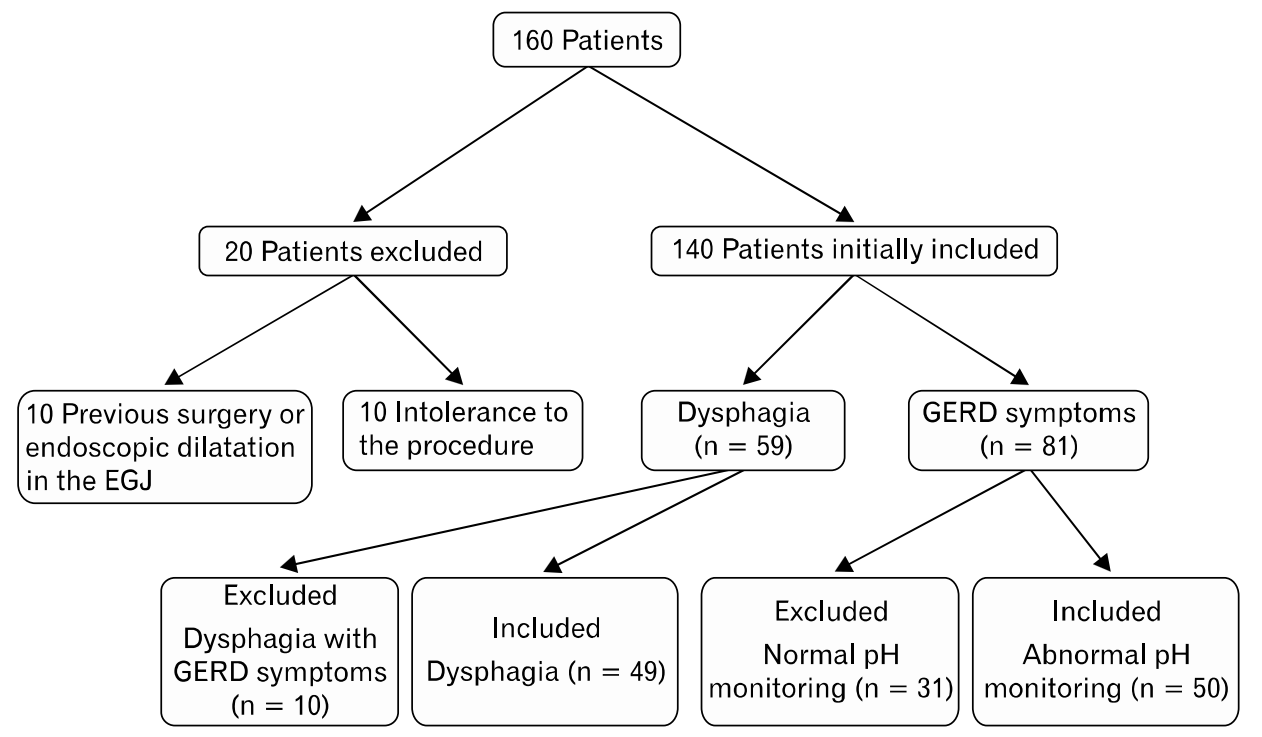

Figure 1. Patients flowchart. EGJ, esophagogastric junction; GERD, gastroesophageal reflux disease.
Table 1. Characteristics of Patients Undergoing High-resolution Manometry

\begin{tabular}{lccc}
\hline & \multicolumn{3}{c}{ Patients characteristics $(\mathrm{N}=99)$} \\
\cline { 2 - 4 } & $\begin{array}{c}\text { Dysphagia } \\
(\mathrm{n}=49)\end{array}$ & $\begin{array}{c}\text { GERD } \\
(\mathrm{n}=50)\end{array}$ & $P$-value \\
\hline Age (mean $\pm \mathrm{SD}, \mathrm{yr})$ & $51.8 \pm 15.3$ & $50.5 \pm 14.5$ & 0.561 \\
Female (n [\%]) & $33(67.4)$ & $26(52.0)$ & 0.119 \\
BMI (mean $\left.\pm \mathrm{SD}, \mathrm{kg} / \mathrm{m}^{2}\right)$ & $26.4 \pm 3.6$ & $27.7 \pm 4.7$ & 0.328 \\
\hline
\end{tabular}

GERD, gastroesophageal reflux disease; SD, standard deviation; F, female; BMI, body mass index.

Statistical method: Mann-Whithey U and Chi-Square.

graphic characteristics of the 2 groups are shown in Table 1 . All participants signed an informed consent to perform the procedures. The study was approved by the 12 de Octubre University Hospital's Ethics Committee.

\section{High-resolution Manometry Protocol}

HRM was performed using a solid-state manometric assembly with 36 circumferential sensors spaced at $1-\mathrm{cm}$ intervals and an outer diameter of $4.2 \mathrm{~mm}$ Manoscan (Given Scientific Instruments Inc, Los Angeles, CA, USA). Prior to recording, the transducers were calibrated at 0 and $300 \mathrm{mmHg}$ with applying an external pressure. Manometric studies were performed after withholding medicines known to affect gastrointestinal function for at least 4 days and following an 8 hours fast. The probe was inserted through a nostril, in the sitting position and positioned to record from the hypopharynx to the stomach with at least three intragastric sensors. The catheter was fixed with tape to the patient's nose. For 5 minutes the patients got used to the probe. Then, the recording started in the sitting position with a 30 -second basal period with no deglutitions in order to obtain the sphincter pressures, followed by ten $5-\mathrm{mL}$ deglutitions every 20 seconds, so that the peristaltic wave could be finished and the LES pressure to return to the baseline. Then, the study was repeated in the supine position with the same sequence as before. If the patient swallowed twice or the interval between swallows was under 20 seconds, the deglutitions were not considered interpretable for the analysis. The final analysis required ten interpretable deglutitions in both positions. ${ }^{18}$

\section{Twenty-four-hour pH-monitoring Protocol}

Twenty-four-hour ambulatory $\mathrm{pH}$-monitoring without a proton pump inhibitors treatment was performed on patients with GERD symptoms. The sensor was placed at $5 \mathrm{~cm}$, above the upper limit of the LES determined by HRM. The study catheter was attached to an ambulatory recorder (Matla Systems Inc, Madrid, Spain). Patients were encouraged to carry out their normal daily activities: to sleep and eat as usually. Each patient was given a diary to record the schedule and duration of their meals, body position changes and symptoms.

\section{Data Analysis}

Manometric data were analyzed using Mano View ${ }^{\mathrm{TM}}$ analysis software version 3.0 (Given Scientific Instruments Inc, Los Angeles, CA, USA).

EGJ was classified depending on the separation between the LES and crural diaphragm: type I (normal) $<1 \mathrm{~cm}$, type II be- 
tween 1-2 cm, and type III (hiatal hernia) when the distance is over $2 \mathrm{~cm} .{ }^{5,19}$ End expiratory EGJ pressure was measured while at rest in both positions. Four seconds integrated relaxation pressure (IRP-4s) was measured using the automated analysis tool in Mano View. ${ }^{1,8}$ IRP-4s normal value has been defined as under $15 \mathrm{mmHg}^{8,9}$ in the supine and under $11 \mathrm{mmHg}$ in the upright position. ${ }^{12}$ Esophageal contractions were analyzed in both positions. ${ }^{1,7-9}$ The following parameters were evaluated in both positions: (1) LES: mean basal and IRP-4s, intra-abdominal length, and upper limit; (2) esophageal body (EB): length, percentage of peristaltic, simultaneous, failed and premature contractions, mean wave amplitude, mean wave duration, mean distal contractile integral (DCI), contractile front velocity, distal latency, and esophageal intrabolus pressure (IBP).

Two experienced researchers performed HRM and reviewed manually all the deglutitions of each patient in both positions. A final diagnosis for LES, EGJ morphology, and EB was made with the obtained parameters and according to the diagnostic criteria proposed by the Chicago group (2012 classification). ${ }^{9}$ The normal published values for each position were used. ${ }^{9}$ LES diagnosis was divided into 3 groups: analysis as normal, hypotensive, and functional obstruction. Hypotensive LES was considered when basal LES pressure was $<10 \mathrm{mmHg}$ and normal IRP-4s ( $<15 \mathrm{mmHg}$ in supine and $<11 \mathrm{mmHg}$ in upright). Functional obstruction was considered when IRP-4s $>15 \mathrm{mmHg}$ in supine and $>11 \mathrm{mmHg}$ in upright. ${ }^{12}$ The EB diagnosis was divided into 3 main groups: analysis as normal, weak peristalsis, and specific motor disorders (achalasia, diffuse esophageal spasm, nutcracker, and hypercontractile). Distal esophageal spasm was considered when distal latency was $<4.5$ seconds in at least $20 \%$ of contractions and hypercontractile if DCI was $>8000 \mathrm{mmHg}$. $\mathrm{cm} \cdot \mathrm{sec}$ in supine and $>2500 \mathrm{mmHg} \cdot \mathrm{cm} \cdot \mathrm{sec}$ upright. ${ }^{9,12}$ Weak peristalsis was defined according to Chicago classification (2012): (1) frequent failed peristalsis when more than $30 \%$ but less than $100 \%$ failed contractions and normal IRP. Contractions were considered failed when minimal $(<3 \mathrm{~cm})$ integrity of the $20 \mathrm{mmHg}$ isobaric contour distal to the proximal pressure was observed, (2) small breaks when more than 30\% small breaks $(2-5 \mathrm{~cm})$ in the $20 \mathrm{mmHg}$ isobaric contour and normal IRP, and (3) large breaks when more than $20 \%$ breaks $(>5 \mathrm{~cm}$ ) in the 20 $\mathrm{mmHg}$ isobaric contour and normal IRP. Both subgroups were considered together for analysis.

Patients were classified as having GERD when the total time with $\mathrm{pH}<4$ was over $4.5 \%$ according to DeMeester reference values. ${ }^{20}$ Reflux symptom association was not used in the final di- agnosis for GERD as the aim of our study was to include only patients with abnormal acid reflux.

\section{Statistical Methods}

HRM quantitative data for both sitting and supine positions were described with mean or median, and standard deviation or interquartile range. Comparisons of quantitative and categorical variables were carried out with the Mann-Whitney and the Chisquare test, respectively. Statistical significance of mean paired differences between body positions in HRM data was calculated with a paired $t$ test and Wilcoxon signed rank test. HRM differences in each parameter between body positions were compared between the 2 groups (dysphagia and GERD symptoms) with non-parametric Wilcoxon signed rank test.

Esophageal motility disorders were described for both body positions with absolute and relative frequencies. To assess the statistical significance of the differences in body positions for the distribution of esophageal motility disorders, a test of symmetry for paired data was performed. Percentage of agreement and reliability estimates (unweighted kappa statistic) for the classification of esophageal motility disorders between sitting and supine positions were presented with a $95 \%$ confidence interval. ${ }^{21}$ According to Landis and Koch, ${ }^{22}$ kappa values correspond to the range slight to fair $(<0.40)$, moderate $(0.41-0.60)$, substantial (0.61$0.80)$, and almost perfect agreement $(>0.81)$. The esophageal motility disorders, the agreement and reliability estimates were computed for the 2 indication groups. The differences between kappa statistics were evaluated. The data analysis was generated using SAS software (SAS Institute Inc, Cary, NC, USA).

\section{Results}

Patient's characteristics are shown in Table 1. HRM parameter results depending on the body position in patients with dysphagia and GERD are described in Table 2. IRP-4s and the percentage of peristaltic waves were significantly lower in the sitting position. Mean wave amplitude, mean wave duration, DCI, IBP, and distal latency were lower when sitting than when supine. Patients with dysphagia and GERD had a higher contractile front velocity in the sitting position than in the supine position. The differences in each HRM parameter between the sitting and supine positions were similar in both groups (Table 2).

HRM results in patients with dysphagia changed significantly in the final diagnosis for $\mathrm{EB}$ as more distal spasm and weak peristalsis ( $P=0.024$, Fig. $2 \mathrm{C})$ were identified in the sit- 
Table 2. High-resolution Manometry Parameter Results Depending on the Body Position in Patients With Esophageal Dysphagia and Gastroesophageal Reflux Disease Symptoms

\begin{tabular}{|c|c|c|c|c|c|c|c|}
\hline \multirow[b]{2}{*}{ HRM parameters } & \multicolumn{3}{|c|}{ Dysphagia $(\mathrm{n}=49)$} & \multicolumn{3}{|c|}{$\operatorname{GERD}(\mathrm{n}=50)$} & \multirow{2}{*}{$\begin{array}{c}\text { Differences }^{2} \\
P \text {-value }\end{array}$} \\
\hline & $\begin{array}{c}\text { Sitting } \\
\text { Mean } \pm \text { SD } \\
\text { Median (IQR) }\end{array}$ & $\begin{array}{c}\text { Supine } \\
\text { Mean } \pm \mathrm{SD} \\
\text { Median }(\mathrm{IQR})\end{array}$ & $P$-value & $\begin{array}{c}\text { Sitting } \\
\text { Mean } \pm \text { SD } \\
\text { Median (IQR) }\end{array}$ & $\begin{array}{c}\text { Supine } \\
\text { Mean } \pm \text { SD } \\
\text { Median (IQR) }\end{array}$ & $P$-value & \\
\hline LES pressure (mmHg) & $\begin{array}{c}14.1 \pm 12.5 \\
10.5(5.9-19.8)\end{array}$ & $\begin{array}{c}16.2 \pm 9.6 \\
14.1(9.0-20.5)\end{array}$ & 0.126 & $\begin{array}{c}9.1 \pm 13.1 \\
5.2(2.2-11.1)\end{array}$ & $\begin{array}{c}11.3 \pm 7.0 \\
10.4(5.4-15.8)\end{array}$ & 0.206 & 0.687 \\
\hline $\mathrm{IRP}(\mathrm{mmHg})$ & $\begin{array}{c}10.2 \pm 6.0 \\
8.2(6.9-15)\end{array}$ & $\begin{array}{c}12.3 \pm 5.5 \\
11.5(7.1-16.7)\end{array}$ & 0.007 & $\begin{array}{c}5.9 \pm 4.2 \\
5.2(2.6-7.8)\end{array}$ & $\begin{array}{c}9.5 \pm 5.7 \\
7.8(5.6-11.9)\end{array}$ & $<0.001$ & 0.281 \\
\hline$\%$ peristaltic waves & $\begin{array}{c}61.0 \pm 34.2 \\
61(44-75)\end{array}$ & $\begin{array}{l}72.9 \pm 34.6 \\
90(60-100)\end{array}$ & 0.002 & $\begin{array}{c}67.4 \pm 29.6 \\
70(40-90)\end{array}$ & $\begin{array}{l}80.4 \pm 25.6 \\
90(70-100)\end{array}$ & 0.001 & 0.692 \\
\hline$\%$ simultaneous & $\begin{array}{c}18.8 \pm 28.7 \\
1(0-30)\end{array}$ & $\begin{array}{c}14.7 \pm 27.6 \\
0(0-10)\end{array}$ & 0.142 & $\begin{array}{c}11.0 \pm 16.3 \\
10(0-10)\end{array}$ & $\begin{array}{c}10.2 \pm 20.3 \\
0(0-10)\end{array}$ & 0.678 & 0.979 \\
\hline$\%$ failed waves & $\begin{array}{c}20 \pm 28.1 \\
10(0-20)\end{array}$ & $\begin{array}{c}12.4 \pm 23.4 \\
0(0-10)\end{array}$ & 0.006 & $\begin{array}{c}21.6 \pm 28.5 \\
10(0-30)\end{array}$ & $\begin{array}{c}9.6 \pm 18.5 \\
0(0-10)\end{array}$ & 0.001 & 0.238 \\
\hline$\%$ premature waves & $\begin{array}{c}8.4 \pm 15.9 \\
0(0-1)\end{array}$ & $\begin{array}{c}5.5 \pm 13.2 \\
0(0-0)\end{array}$ & 0.157 & $\begin{array}{c}6.6 \pm 12.7 \\
0(0-0)\end{array}$ & $\begin{array}{c}6.2 \pm 12.3 \\
0(0-10)\end{array}$ & 0.802 & 0.309 \\
\hline MWA & $\begin{array}{c}66.2 \pm 41.7 \\
60.3(31.0-89.0)\end{array}$ & $\begin{array}{c}82.5 \pm 56.6 \\
74.9(31.4-121.1)\end{array}$ & $<0.001$ & $\begin{array}{c}58.2 \pm 32.1 \\
49.8(31.4-85.1)\end{array}$ & $\begin{array}{c}70.7 \pm 37.1 \\
61.5(45.2-97.3)\end{array}$ & $<0.001$ & 0.705 \\
\hline MWD & $\begin{array}{c}3.9 \pm 1.5 \\
3.5(3.2-4.1)\end{array}$ & $\begin{array}{c}4.0 \pm 2.0 \\
3.7(3.1-4.3)\end{array}$ & 0.358 & $\begin{array}{c}3.7 \pm 0.8 \\
3.7(3.1-4.2)\end{array}$ & $\begin{array}{c}4.0 \pm 1.0 \\
3.9(3.4-4.3)\end{array}$ & 0.038 & 0.350 \\
\hline DCI & $\begin{array}{c}1768.6 \pm 1777.9 \\
971.9 \\
(559.3-2290.8)\end{array}$ & $\begin{array}{c}2746.8 \pm 2625.2 \\
2269.2 \\
(669.7-3858.3)\end{array}$ & $<0.001$ & $\begin{array}{c}1129.9 \pm 1024.3 \\
896.7 \\
(351.2-1554.7)\end{array}$ & $\begin{array}{c}1972.4 \pm 1755.9 \\
1362.5 \\
(959.1-2832.2)\end{array}$ & $<0.001$ & 0.221 \\
\hline $\mathrm{CFV}$ & $\begin{array}{l}21.8 \pm 83.0 \\
4.5(3.1-7.7)\end{array}$ & $\begin{array}{l}11.8 \pm 38.9 \\
3.5(2.7-5.6)\end{array}$ & 0.136 & $\begin{array}{l}8.9 \pm 14.4 \\
4.3(3-7.6)\end{array}$ & $\begin{array}{c}4.0 \pm 13.9 \\
3.7(2.8-4.7)\end{array}$ & 0.179 & 0.423 \\
\hline Distal latency & $\begin{array}{c}5.7 \pm 0.9 \\
6.1(4.6-6.5)\end{array}$ & $\begin{array}{c}5.9 \pm 0.7 \\
6.0(5.5-6.6)\end{array}$ & 0.044 & $\begin{array}{c}5.8 \pm 0.8 \\
6.1(5.6-6.5)\end{array}$ & $\begin{array}{c}5.9 \pm 0.7 \\
6.2(5.8-6.5)\end{array}$ & 0.072 & 0.456 \\
\hline IBP & $\begin{array}{c}16.2 \pm 10.0 \\
15.4(8.3-22.5)\end{array}$ & $\begin{array}{c}19.9 \pm 10.9 \\
19.6(12.6-25.9)\end{array}$ & 0.013 & $\begin{array}{c}13.5 \pm 8.4 \\
14.3(7.3-18)\end{array}$ & $\begin{array}{c}17.9 \pm 10.8 \\
17.2(11.1-23.0)\end{array}$ & 0.001 & 0.766 \\
\hline
\end{tabular}

HRM, high-resolution manometry; SD, standard diviation; LES, lower esophageal sphincter; IQR, interquartile range; IRP, integral relaxation pressure; MWA, mean wave amplitude; MWD, mean wave duration; DCI, distal contractile integral; CFV, contractile front velocity; IBP, intrabolus pressure.

${ }^{a}$ Differences between sitting-supine in dysphagia and sitting-supine in gastroesophageal reflux disease.

Statistical methods: paired $t$ test.

ting position. Similarly, more EGJ outflow obstruction (IRP-4s cut-off of $11 \mathrm{mmHg}$ ) was found in the same position, although the differences were not significant $(P=0.064$, Fig. $2 \mathrm{~A})$. We did not find significant changes in EGJ morphology $(P=0.228$, Fig. 2B) either.

Patients with GERD had different HRM diagnoses for LES, EGJ morphology, and EB depending on the body position ( $P=0.063, P=0.017, P=0.041$, respectively; Fig. 3). More hypotensive LES and EGJ type III (hiatal hernia) were identified in the sitting position (Fig. 3A and 3B). Weak peristalsis was also diagnosed more frequently in the sitting position (Fig. 3C) and was the most prominent for EB in patients with dysphagia and GERD. Weak contractions were subanalyzed in the 2 body positions. Changing from sitting to supine $46.3 \%$ of the degluti- tions normalized the integrity in the $20 \mathrm{mmHg}$ isobaric contour. In the sitting position, 205 of 990 total deglutitions had weak peristalsis. One hundred and thirty-six of them failed in 50 large and 19 small breaks in the $20 \mathrm{mmHg}$ isobaric contour, respectively. In supine, 110 of 990 total deglutitions had weak peristalsis, of which 58 failed in 23 having large and 29 small breaks (Fig. 4).

HRM plots in Figure 5 show the variations depending on the body position. The percent agreement between the body positions was similar in the dysphagia and GERD groups for "LES diagnosis" (51\% in dysphagia and 58\% in GERD) and for "EB diagnosis" (67\% in dysphagia and $60 \%$ in GERD). The reliability (kappa) between the body positions was also similar in the dysphagia and GERD groups for "LES diagnosis" (dysphagia, 
A

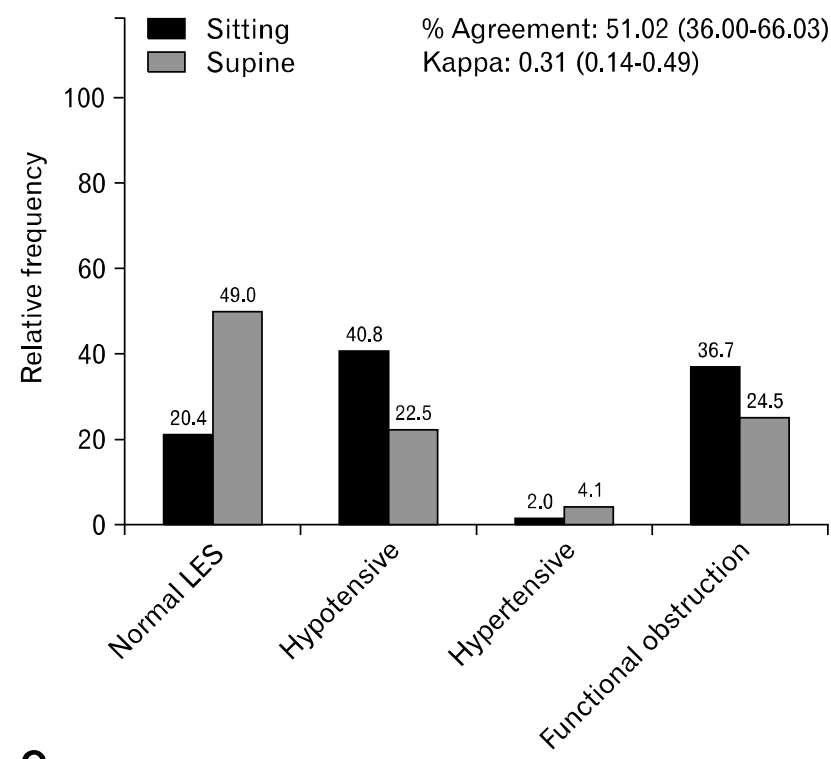

C

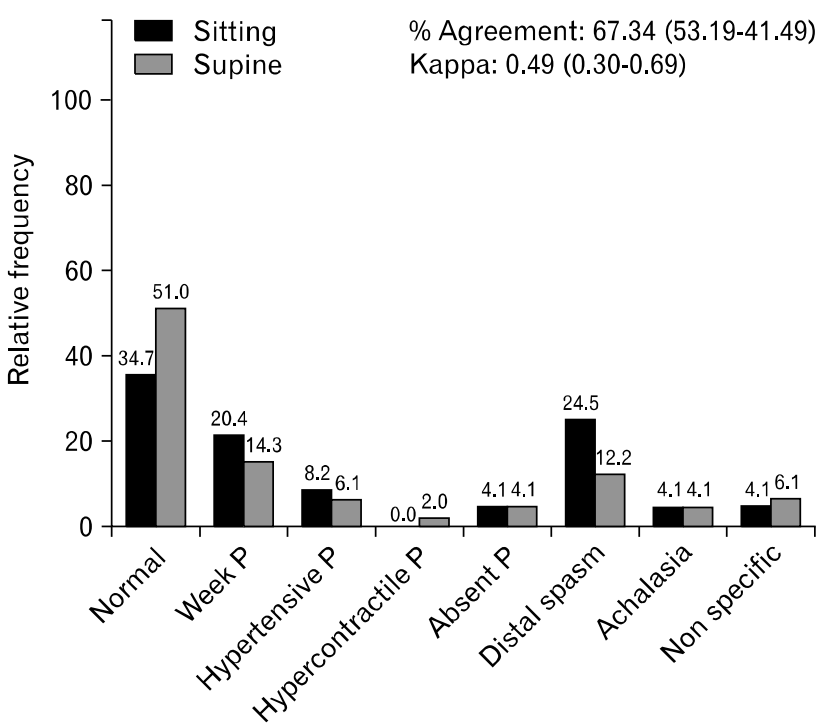

0.32 [0.14-0.49] and GERD, $0.31[0.10-0.52] ; P=0.960)$ and for "EB diagnosis" (dysphagia 0.49 [0.30-0.69] and GERD 0.39 [0.20-0.59]; $P=0.480$ ). However, the agreement between the body positions for "EGJ morphology" was higher in dysphagia $(85.7 \%)$ than in GERD (66\%). The reliability was also higher in dysphagia (0.81 [0.68-0.94] than in GERD 0.55 [0.37-0.73]; $P$ $=0.020)$.

Therefore, we observed that the EGJ moved orally when the position changed from sitting to supine, although the displacement was not statistically significant. Both the LES and the pressure inversion point (PIP) move orally from sitting to supine
B

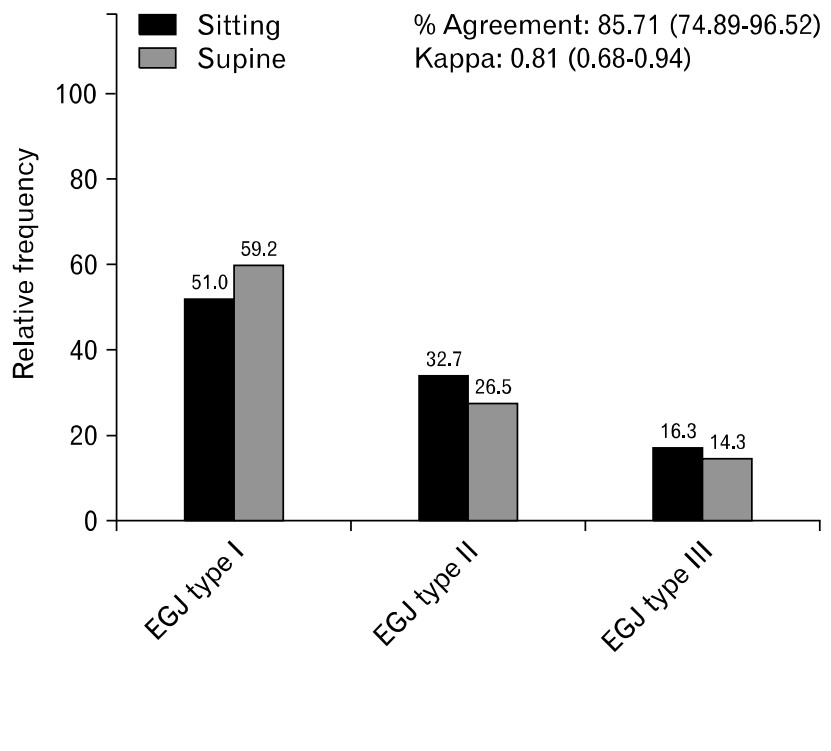

Figure 2. Manometric changes according to the body position in patients with dysphagia. (A) Change in lower esophageal sphincter (LES) diagnosis in patients with dysphagia according to the body position. (B) esophagogastric junction (EGJ) morphology in patients with dysphagia according to the body position. (C) Change in esophageal body diagnosis in patients with dysphagia according to the body position. $\mathrm{P}$, peristalsis.

(median LES proximal border sitting: $42.2(40.6-44.4) \mathrm{cm}$, supine: $42.1(40.0-44.6) \mathrm{cm}, P=0.522$; PIP sitting: 44.8 $(42.2-47.0) \mathrm{cm}$, supine: $44.5(42.3-46.7) \mathrm{cm}, P=0.138)$. In patients with GERD and EGJ disruption (type II and III), the EGJ was longer in the sitting position than in supine but the change was not significant (EGJ total length sitting: 4.5 [3.4-5.2] cm, supine: $4[3.2-5.1] \mathrm{cm}, P=0.247)$.

\section{Discussion}

There is increased evidence that the body position can influ- 
A

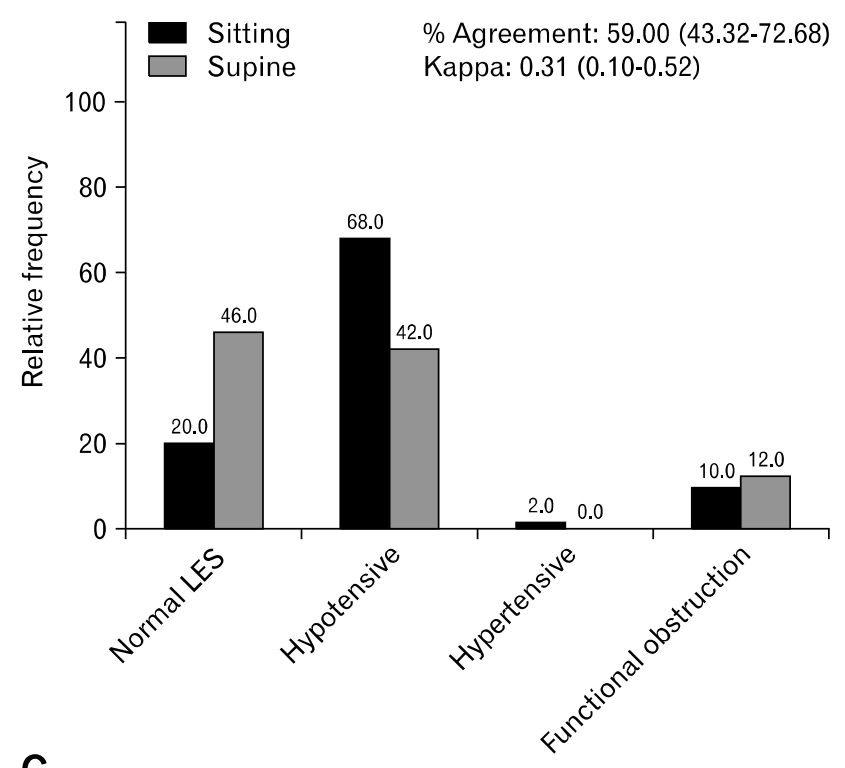

C

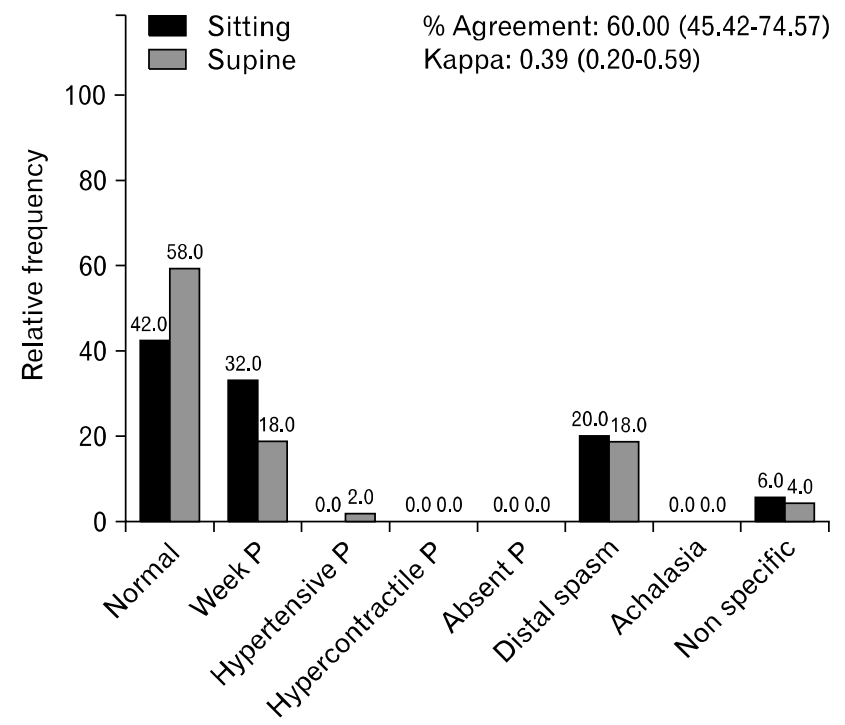

B

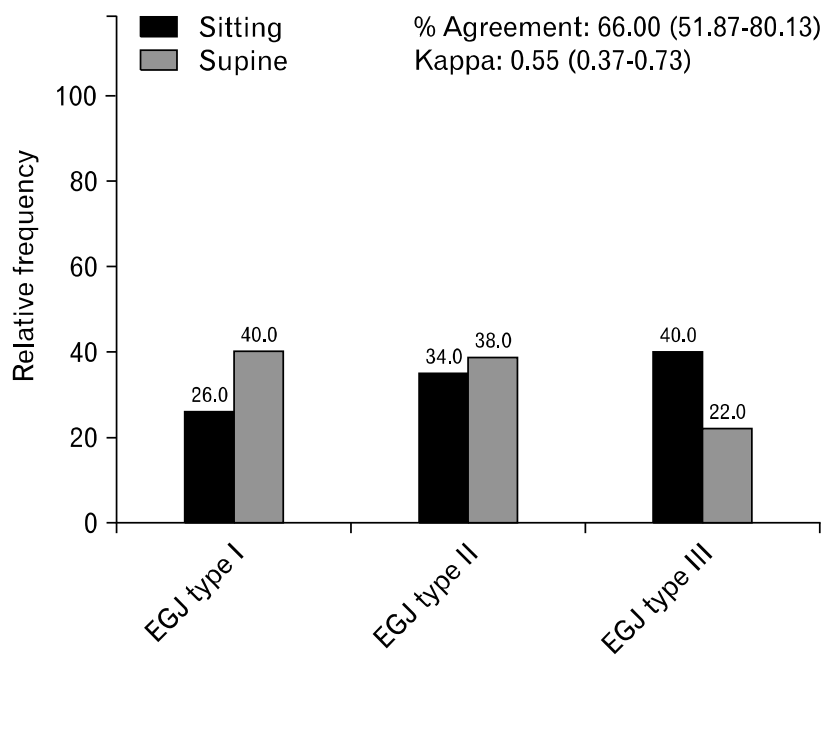

Figure 3. Manometric changes according to the body position in patients with gastroesophageal reflux disease (GERD). (A) Change in lower esophageal sphincter (LES) diagnosis in patients with GERD according to the body position. (B) Change in esophagogastric junction (EGJ) morphology in patients with GERD according to the body position. (C) Change in esophageal body diagnosis in patients with GERD according to the body position. $\mathrm{P}$, peristalsis.

A

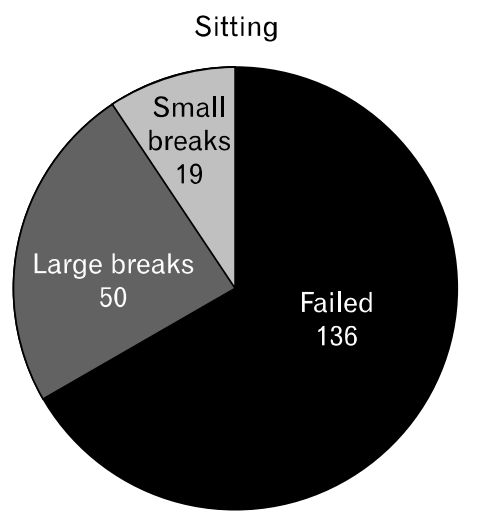

990 total swallows of which 205 were failed
B

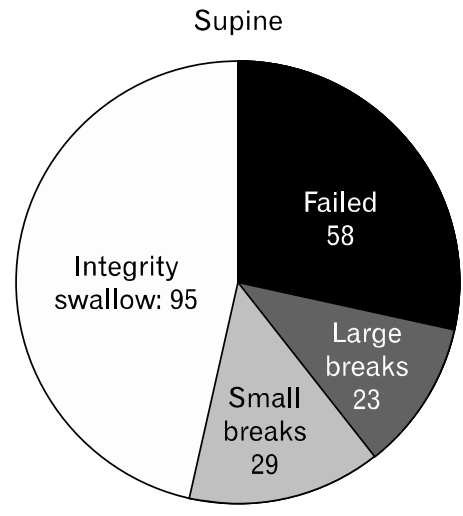

990 total swallows of which 110 were failed
Figure 4. Weak contractions description and the recovery of the integrity in 95 deglutitions when moving from sitting to supine. (A) In total of 990, 205 weak contractions were observed in the sitting position. (B) In total of 990, 110 weak contractions were found in the supine position. 

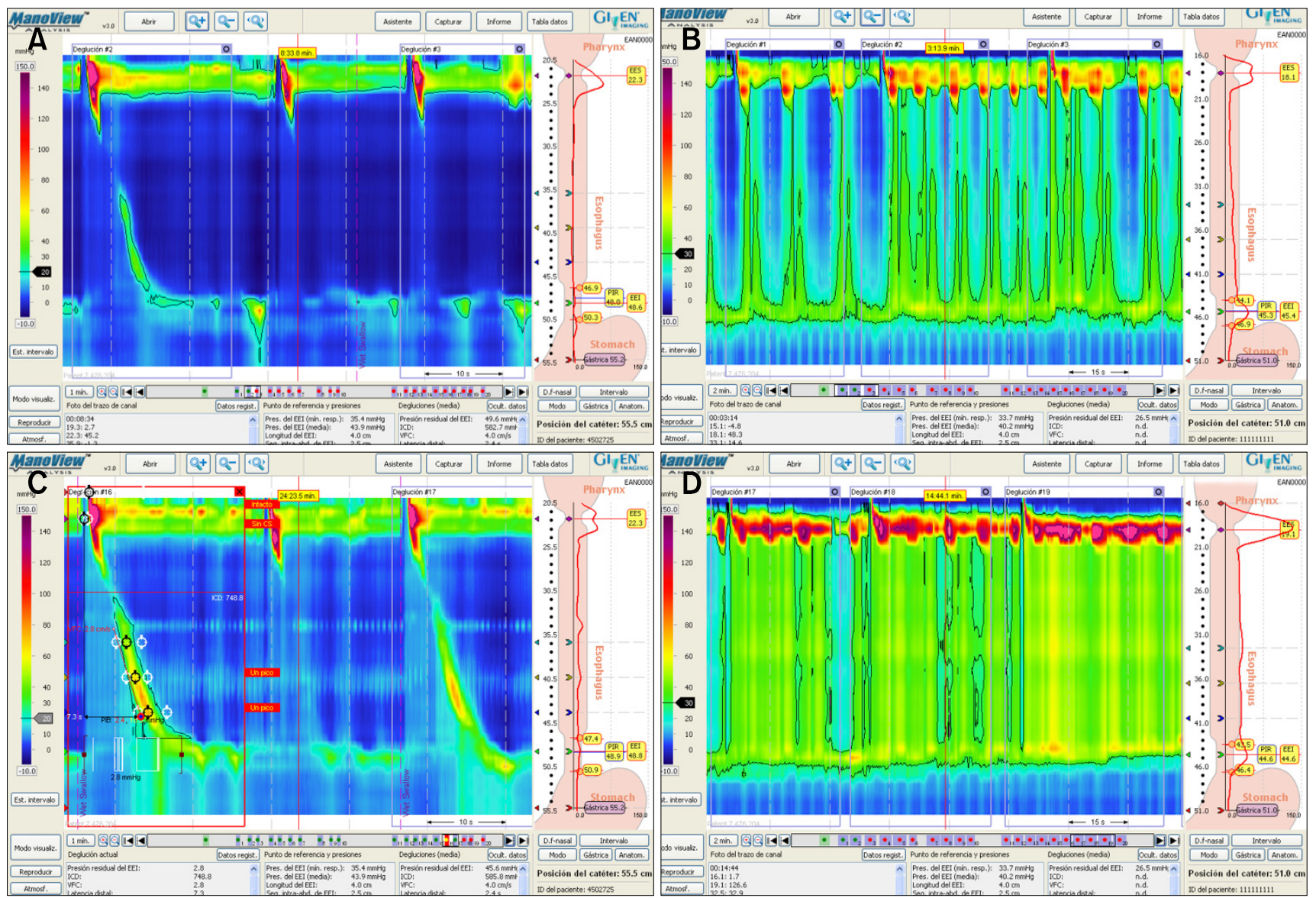

Figure 5. High resolution manometry (HRM) plots according to the body position. (A) HRM plot that shows weak peristalsis and hypotensive lower esophageal sphincter (LES) in a patient diagnosed with gastroesophageal reflux disease in the sitting position. (B) As per above (A) but in the supine position showing normal peristalsis and LES, so the diagnosis was different from that in (A). (C) HRM plot in a patient with achalasia type II in the sitting position. (D) As per above (C) in supine showing positive pressure in esophagus but the final diagnosis was the same in both positions.

ence the results in HRM. We have also demonstrated it in our study which is compatible with others. ${ }^{23,24}$ However, up to now the accepted protocol and classification of esophageal motor disorders have been for the supine position. The esophagus and adjacent structures, such as the crural diaphragm, are influenced by the change in the body position. It is known that Trendelenburg and supine position increase the intragastric pressure and as a consequence the LES pressure increases as a protective mechanism to prevent reflux of gastric contents. ${ }^{25}$ Furthermore, the workload required to transport the bolus decreases in the upright position, ${ }^{15}$ mainly as a consequence of gravity.

As we have shown in our study, LES basal pressure and IRP were lower in the sitting position and increased in supine as described by other authors. ${ }^{24}$ This happened both in patients with dysphagia and patients with GERD. In dysphagia patients we observed some important changes from supine to sitting position.
More normal peristalsis and EGJ relaxation were diagnosed in supine and more distal spasm, weak peristalsis and EGJ outflow obstruction in the sitting position. ${ }^{12}$ As previously described, the LES basal pressure tends to be lower in the sitting position but also we found more EGJ functional obstruction in the same position applying the IRP-4s cut-off $11 \mathrm{mmHg}$ referral value published for this position. ${ }^{12}$ This discrepancy was noted by Xiao et $\mathrm{al}^{12}$ in healthy subjects; they attributed it to the effect of gravity. In this aspect, we consider the sitting position to be more accurate for diagnosing patients with dysphagia.

In our study IBP was higher in both positions, more in patients with dysphagia than in patients with GERD, just as described by other authors, too. ${ }^{26}$ IBP is an important parameter for predicting bolus clearance. ${ }^{8}$ However, the behavior of the IBP in the 2 body positions was similar in patients with dysphagia and patients with GERD (Table 2). 
The changes observed in patients with GERD according to the body position were remarkable. We detected more hypotensive LES, EGJ type III (hiatal hernia), and weak peristalsis in patients with GERD in the sitting position. It has been demonstrated that the distance between the LES and crural diaphragm landmarks is variable as hiatal hernia is a dynamic entity. ${ }^{13}$ In our study, these changes are more evident in the sitting than in the supine position, as the EGJ type II and III were longer in the sitting position. Also, when moving from sitting to supine the LES and the PIP tends to move orally although the change was not significant.

It seems that LES and EGJ functioned as an intact anti-reflux barrier in supine and became incompetent in some subjects in the upright position, and the "protective effect" of the supine position is lost according to other authors. ${ }^{16}$ As a consequence, body position impacts LES competency in patients with upright reflux and would not be detected by manometry in the supine position. ${ }^{16}$ To this effect, we found a significant higher proportion of hypotensive LES and EGJ disruption in the sitting position in patients with GERD. This fact might be important because an active person is mostly upright during the day and the HRM performed in the sitting position provides a better insight into the pathological mechanisms involved in GERD.

Furthermore, swallowing occurs normally in upright position rather than in supine and the tolerance to the procedures is accordingly better in the upright position, although we did not analyze specifically this aspect. For all these reasons, HRM performed in the sitting position seems to be more accurate for studying patients with dysphagia and GERD.

There are some limitations of our study. We did not measure the esophageal transit simultaneously in the 2 positions nor did administer any solid bolus. This may have been important, particularly in patients with dysphagia. ${ }^{27}$ But, when the study was carried out, impedance-HRM was not available at our center.

The main strength of our study is that, at present, there are no other studies that analyze the results obtained in HRM from both body positions in patients with dysphagia and GERD using the recent reference values published for each position. ${ }^{12}$

In conclusion, body position can influence the results obtained in HRM using the normal values published for each position. The sitting position appears to be more favorable for the study of patients with dysphagia and GERD and it is also more tolerable and physiological for patients. Our results support the development of a validated protocol for the sitting position, as we have demonstrated that there are discrepancies in the diagnosis using the specific normal values published for each position. Even though the supine position is recommended by most of the expert working groups, we consider that this does not cover all the pathophysiological aspects that need to be explored. More studies are needed in this area to adopt an evidence-based strategy focused on the methodological aspect of the technique as well as diagnostic criteria to be applied in clinical practice.

\section{References}

1. Pandolfino JE, Ghosh SK, Zhang Q, Jarosz A, Shah N, Kahrilas PJ. Quantifying EGJ morphology and relaxation with high-resolution manometry: a study of 75 asymptomatic volunteers. Am J Physiol Gastrointest Liver Physiol 2006;290:G1033-G1040.

2. Ghosh SK, Pandolfino JE, Zhang Q, Jarosz A, Shah N, Kahrilas PJ. Quantifying esophageal peristalsis with high-resolution manometry: a study of 75 asymptomatic volunteers. Am J Physiol Gastrointest Liver Physiol 2006;290:G988-G997.

3. Ciriza-de-Los-Ríos C, Canga-Rodríguez-Valcárcel F. High-resolution manometry and impedance- $\mathrm{pH} /$ manometry: novel techniques for the advancement of knowledge on esophageal function and their clinical role. Rev Esp Enferm Dig 2009;101:861-869.

4. Ghosh SK, Pandolfino JE, Zhang Q, Jarosz A, Kahrilas PJ. Deglutitive upper esophageal sphincter relaxation: a study of $75 \mathrm{vol}-$ unteer subjects using solid-state high-resolution manometry. Am J Physiol Gastrointest Liver Physiol 2006;291:G525-G531.

5. Ciriza-de-Los-Ríos C, Canga-Rodríguez-Valcárcel F, Castel de Lucas I, Lora-Pablos D, de-la-Cruz-Bértolo J, Castellano Tortajada G. How useful is esophageal high resolution manometry in diagnosing gastroesophageal junction disruption: causes affecting this disruption and its relationship with manometric alterations and gastroesophageal reflux. Rev Esp Enferm Dig 2014;106:22-29.

6. Bredenoord AJ, Hebbard GS. Technical aspects of clinical high-resolution manometry studies. Neurogastroenterol Motil 2012;24(suppl 1): 5-10.

7. Pandolfino JE, Ghosh SK, Rice J, Clarke JO, Kwiatek MA, Kahrilas PJ. Classifying esophageal motility by pressure topography characteristics: a study of 400 patients and 75 controls. Am J Gastroenterol 2008;103:27-37.

8. Pandolfino JE, Fox MR, Bredenoord AJ, Kahrilas PJ. High-resolution manometry in clinical practice: utilizing pressure topography to classify oesophageal motility abnormalities. Neurogastroenterol Motil 2009;21:796-806.

9. Bredenoord AJ, Fox M, Kahrilas PJ, et al. Chicago classification criteria of esophageal motility disorders defined in high resolution esophageal pressure topography. Neurogastroenterol Motil 2012; 24(suppl 1):57-65.

10. Pandolfino JE, Kahrilas PJ. New technologies in the gastrointestinal clinic and research: impedance and high-resolution manometry. World J Gastroenterol 2009; 14;15:131-138.

11. Weijenborg PW, Kessing BF, Smout AJ, Bredenoord AJ. Normal values for solid-state esophageal high-resolution manometry in a European population; an overview of all current metrics. Neurogastroenterol Motil 2014;26:654-659. 
12. Xiao Y, Read A, Nicodème F, Roman S, Kahrilas PJ, Pandolfino JE. The effect of a sitting vs supine posture on normative esophageal pressure topography metrics and Chicago classification diagnosis of esophageal motility disorders. Neurogastroenterol Motil 2012;24: e509-e516.

13. Bredenoord AJ, Weusten BL, Timmer R, Smout AJ. Intermittent spatial separation of diaphragm and lower esophageal sphincter favors acidic and weakly acidic reflux. Gastroenterology 2006;130: 334-340.

14. Scheffer RC, Bredenoord AJ, Hebbard GS, Smout AJ, Samsom M. Effect of proximal gastric volume on hiatal hernia. Neurogastroenterol Motil 2010;22:552-556, e120.

15. Bernhard A, Pohl D, Fried M, Castell DO, Tutuian R. Influence of bolus consistency and position on esophageal high-resolution manometry findings. Dig Dis Sci 2008;53:1198-1205.

16. Hoppo T, Komatsu Y, Nieponice A, Schrenker J, Jobe BA. Toward an improved understanding of isolated upright reflux: positional effects on the lower esophageal sphincter in patients with symptoms of gastroesophageal reflux. World J Surg 2012;36:1623-1631.

17. Tsuboi K, Hoshino M, Srinivasan A, et al. Insights gained from symptom evaluation of esophageal motility disorders: a review of 4,215 patients. Digestion 2012;85:236-242.

18. Roman S, Kahrilas PJ, Boris L, Bidari K, Luger D, Pandolfino JE. High-resolution manometry studies are frequently imperfect but usually still interpretable. Clin Gastroenterol Hepatol 2011;9:10501055.

19. Pandolfino JE, Kim H, Ghosh SK, Clarke JO, Zhang Q, Kahrilas
PJ. High-resolution manometry of the EGJ: an analysis of crural diaphragm function in GERD. Am J Gastroenterol 2007;102:10561063.

20. Bodger K, Trudgill N. Guidelines for oesophageal manometry and pH monitoring. British Society of Gastroenterology 2006:1-11.

21. Kottner J, Audigé L, Brorson S, et al. Guidelines for reporting reliability and agreement studies (GRRAS) were proposed. J Clin Epidemiol 2011;64:96-106

22. Landis JR, Koch GG. The measurement of observer agreement for categorical data. Biometrics 1977;33:159-174

23. Roman S, Damon H, Pellissier PE, Mion F. Does body position modify the results of oesophageal high resolution manometry? Neurogastroenterol Motil 2010;22:271-275.

24. Sweis R, Anggiansah A, Wong T, Kaufman E, Obrecht S, Fox M. Normative values and inter-observer agreement for liquid and solid bolus swallows in upright and supine positions as assessed by esophageal high-resolution manometry. Neurogastroenterol Motil 2011; 23:509-e198.

25. de Leon A, Thörn SE, Ottosson J, Wattwil M. Body positions and esophageal sphincter pressures in obese patients during anesthesia. Acta Anaesthesiol Scand 2010;54:458-463.

26. Pandolfino JE, Kwiatek MA, Ho K, Scherer JR, Kahrilas PJ. Unique features of esophagogastric junction pressure topography in hiatus hernia patients with dysphagia. Surgery 2010;147:57-64.

27. Park EJ, Lee JS, Lee TH, et al. High-resolution impedance manometry criteria in the sitting position indicative of incomplete bolus clearance. J Neurogastroenterol Motil 2014;20:491-496. 